Article

\title{
Bioactive Indole Derivatives from the South Pacific Marine Sponges Rhopaloeides odorabile and Hyrtios sp.
}

\author{
Arlette Longeon ${ }^{1}$, Brent R. Copp ${ }^{2}$, Elodie Quévrain ${ }^{1}$, Mélanie Roué ${ }^{1}$, Betty Kientz ${ }^{1}$, \\ Thierry Cresteil ${ }^{3}$, Sylvain Petek ${ }^{4}$, Cécile Debitus ${ }^{4}$ and Marie-Lise Bourguet-Kondracki ${ }^{1}$ **
}

1 Laboratoire Molécules de Communication et Adaptation des Micro-organismes, UMR 7245 MNHN-CNRS, Muséum National d'Histoire Naturelle, 57 rue Cuvier (C.P. 54), 75005 Paris, France; E-Mails: longeon@mnhn.fr (A.L.); quevrain@mnhn.fr (E.Q.); mroue@ mnhn.fr (M.R.); kientz@mnhn.fr (B.K.)

2 Department of Chemistry, The University of Auckland, Private Bag 92019, Auckland, New Zealand; E-Mail: b.copp@ auckland.ac.nz (B.R.C.)

3 Institut de Chimie des Substances Naturelles, CNRS UPR 2301, Centre de Recherche de Gif, avenue de la Terrasse, 91198 Gif sur Yvette Cedex, France;

E-Mail: thierry.cresteil@icsn.cnrs-gif.fr (T.C.)

4 Centre Polynésien de Recherche sur la Biodiversité Insulaire, UMR 7138 CNRS, B.P. 529, 98713 Papeete, Tahiti, Polynésie française, France; E-Mails: sylvain.petek@ird.fr (S.P.); cecile.debitus@ird.fr (C.D.)

* Author to whom correspondence should be addressed; E-Mail: bourguet@mnhn.fr; Tel.: +1-140-795-606; Fax: +1-140-793-135.

Received: 13 April 2011; in revised form: 16 May 2011 / Accepted: 17 May 2011 /

Published: 24 May 2011

\begin{abstract}
Indole derivatives including bromoindoles have been isolated from the South Pacific marine sponges Rhopaloeides odorabile and Hyrtios sp. Their structures were established through analysis of mass spectra and 1D and 2D NMR spectroscopic data. Their potential inhibitory phospholipase $\mathrm{A}_{2}\left(\mathrm{PLA}_{2}\right)$, antioxidant and cytotoxic activities were evaluated. The new derivative 5,6-dibromo-L-hypaphorine (9) isolated from Hyrtios sp. revealed a weak bee venom $\mathrm{PLA}_{2}$ inhibition $\left(\mathrm{IC}_{50} 0.2 \mathrm{mM}\right)$ and a significant antioxidant activity with an Oxygen Radical Absorbance Capacity (ORAC) value of 0.22. The sesquiterpene aureol (4), also isolated from Hyrtios sp., showed the most potent antioxidant activity with an ORAC value of 0.29 .
\end{abstract}


Keywords: indole derivatives; bromoindoles; marine sponge; Rhopaloeides odorabile; Hyrtios sp.; PLA ${ }_{2}$ inhibitor; antioxidant; cytotoxic

\section{Introduction}

A great variety of simple and substituted indole derivatives, including halogenated indoles, bisindoles and tryptamine derivatives, have been previously isolated from marine organisms [1]. Indole derivatives are known to display various bioactivities such as anticancer, antibiotic, and anti-inflammatory activities [2]. Antioxidant activities were also recently reported for some analogues such as 2,2-diphenyl-1-picrylhydrazyl (DPPH) radical scavengers, highlighting an additional bioactivity in the series [3].

In our ongoing search for bioactive compounds within the frame of the CRISP program (Coral Reef Initiative in the South Pacific), the crude extracts of two South Pacific marine sponges were investigated, based on their significant anti-PLA ${ }_{2}$ activities. One specimen of Rhopaloeides odorabile was collected from the Solomon Islands and one specimen of Hyrtios sp. from the Fiji Islands. Fractionation of each of the crude extracts led to the isolation of a series of indole derivatives.

Three known monomeric indoles were isolated from the marine sponge $R$. odorabile and five dibromoindole derivatives, including the new derivative, 5,6-dibromo-L-hypaphorine (9), in addition to the sesquiterpene aureol (4) were obtained from the sponge Hyrtios sp.

The current report describes the isolation of alkaloids 1-9 and structural identification of the new analogue, 5,6-dibromo-L-hypaphorine (9). Anti-PLA 2 , antioxidant and cytotoxic activities of the series were evaluated and are presented.

\section{Results and Discussion}

\subsection{Isolation of Indole Derivatives}

Successive chromatographic fractionation of the $\mathrm{CH}_{2} \mathrm{Cl}_{2}$ extract of $R$. odorabile using silica gel column chromatography and purification of the anti-PLA $A_{2}$ fractions on C18 HPLC afforded three known monoindole alkaloids ( $1 H$-indol-3-yl) oxoacetamide $(\mathbf{1})$ and (1H-indol-3-yl) oxoacetic acid methyl ester (2), both previously isolated from the marine sponge Spongosorites sp. collected off the coast of Jeju Island, Korea [4] and 6-bromoindole-3-carbaldehyde (3) from the marine sponge Pseudosuberites hyalinus [5] (Figure 1).

Chromatographic fractionation of the $\mathrm{CH}_{2} \mathrm{Cl}_{2}$ extract of Hyrtios sp. using silica gel afforded aureol (4), rapidly identified by comparison with literature data [6]. Chromatographic fractionation of the $\mathrm{MeOH}$ extract of Hyrtios sp. using C18 and LH 20 columns followed by successive ODS C18 HPLC revealed the presence of five dibromoalkaloids 5-9. The structures of the known compounds 5-8 were rapidly determined as 5,6-dibromotryptamine 5, $\mathrm{N}$-methyl-5,6-dibromotryptamine (6) [7], $\mathrm{N}, \mathrm{N}$-dimethyl-5,6-dibromotryptamine (7) [8], and 5,6-dibromoabrine (8) [9] by comparison with literature data. The structure of the new metabolite, 5,6-dibromo-L-hypaphorine (9), was obtained 
through detailed examination of mass spectrometric data and extensive 1D and 2D NMR studies (Figure 2).

Figure 1. Structures of indole derivatives 1-3 isolated from the marine sponge Rhopaloeides odorabile<smiles>[R]C(=O)C(=O)c1c[nH]c2ccccc12</smiles>

$1 \mathrm{R}=\mathrm{NH}_{2}$ $2 \mathrm{R}=\mathrm{OCH}_{3}$<smiles>O=Cc1c[nH]c2cc(Br)ccc12</smiles>

3

Figure 2. Structures of compounds 4-9 isolated from the marine sponge Hyrtios sp.

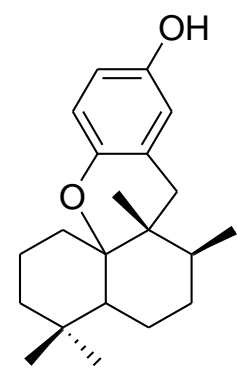

4<smiles>[R]CCc1c[nH]c2cc(Br)c(Br)cc12</smiles>

$5 \mathrm{R}=\mathrm{NH}_{2}$

$6 \mathrm{R}=\mathrm{NHCH}_{3}$

$7 \mathrm{R}=\mathrm{N}\left(\mathrm{CH}_{3}\right)_{2}$<smiles>[R]C([R])Cc1c[nH]c2cc(Br)c(Br)cc12</smiles>

8: $\mathrm{R}_{1}=\mathrm{COOH}, \mathrm{R}_{2}=\mathrm{NHCH}_{3}$

9: $\mathrm{R}_{1}=\mathrm{COO}^{-}, \mathrm{R}_{2}=\mathrm{N}^{+}\left(\mathrm{CH}_{3}\right)_{3}$

\subsection{Structure Elucidation of 5,6-Dibromo-L-hypaphorine (9)}

Compound 9 was isolated as an optically active pale yellow oil, with $[\alpha]^{20}{ }_{\mathrm{D}}+28(c) 0.06$, MeOH-1 N HCl, 8:2). The positive mode ESI mass spectrum of 9 showed a 1:2:1 molecular ion cluster at $m / z$ 402.9, 404.9, 406.9, characteristic of the presence of two bromine atoms and corresponding to the molecular formula $\mathrm{C}_{14} \mathrm{H}_{17} \mathrm{~N}_{2} \mathrm{O}_{2}{ }^{79} \mathrm{Br}_{2}$ for the pseudomolecular ion $[\mathrm{M}+\mathrm{H}]^{+}$at $\mathrm{m} / z$ 402.9667. ${ }^{1} \mathrm{H}$ and ${ }^{13} \mathrm{C} \mathrm{NMR}$ data for 9 in DMSO- $d_{6}$ were similar to those reported for 5,6-dibromoabrine $(\mathbf{8})$, in particular the resonances of three singlet protons in the aromatic region at $\delta_{\mathrm{H}}$ $8.02(1 \mathrm{H}, \mathrm{s}), 7.72(1 \mathrm{H}, \mathrm{s}), 7.27(1 \mathrm{H}, \mathrm{s})$, a methine proton at $\delta_{\mathrm{H}} 3.67(1 \mathrm{H}, \mathrm{dd}, J=10.1,3.3)$, methylene protons at $\delta_{\mathrm{H}} 3.21(2 \mathrm{H}, \mathrm{m})$ and the presence of a carboxylate function at $\delta_{\mathrm{C}} 167.0(\mathrm{C})$. The main difference between 8 and 9 was the presence of a ${ }^{+} \mathrm{Me}_{3}$ cation, indicated by a nine-proton singlet in the ${ }^{1} \mathrm{H}$ NMR spectrum of 9 at $\delta_{\mathrm{H}} 3.17(9 \mathrm{H}, \mathrm{s})$. In addition, two broad singlet protons at $\delta_{\mathrm{H}} 11.20(1 \mathrm{H}$, brs) and $8.45(1 \mathrm{H}$, brs) suggested the presence of an amine and hydroxyl function, respectively. Furthermore, COSY correlations between the methine proton at $\delta_{\mathrm{H}} 3.67$ with methylene protons at $\delta_{\mathrm{H}} 3.21$ and between the amine proton at $\delta_{\mathrm{H}} 11.20$ with proton at $\delta_{\mathrm{H}} 7.27$ indicated the presence of a $\mathrm{CH}_{2}-\mathrm{CH}$ group and a $\mathrm{NH}-\mathrm{CH}$ group, respectively. Five non-protonated aromatic carbons at $\delta_{\mathrm{C}} 135.7$ (C-7a), 128.2 (C-3a), 114.8 (C-6), 112.6 (C-5) and 109.5 (C-3) suggested 5,6 dibromosubstitution of the indole nucleus, which was supported by the observed HMBC correlations as presented in Table 1 
and by comparison with literature values for 8 [9]. Thus, the new alkaloid, was identified as 5,6-dibromo-L-hypaphorine (9), a new member of the hypaphorine family. Halogenation on the benzene ring of tryptophan derivatives does not affect the sign of optical rotation [10], therefore 9 was assigned as L-configuration $(9 S)$ by comparison of its optical rotation value, $[\alpha]^{20}+28(c 0.06$, MeOH-1 N HCl, 8:2), with those reported in the literature for 6-bromo-D $\left([\alpha]^{17}{ }_{\mathrm{D}}-27(c 0.8, \mathrm{MeOH}\right.$, TFA, 8:1)) [11] and L-hypaphorine $\left([\alpha]^{15}+58(c\right.$ unspecified, MeOH, TFA, 8:1)) [12].

Table 1. NMR spectroscopic data of 5,6-dibromo-L-hypaphorine $(\mathbf{9})^{\mathrm{a}}$.

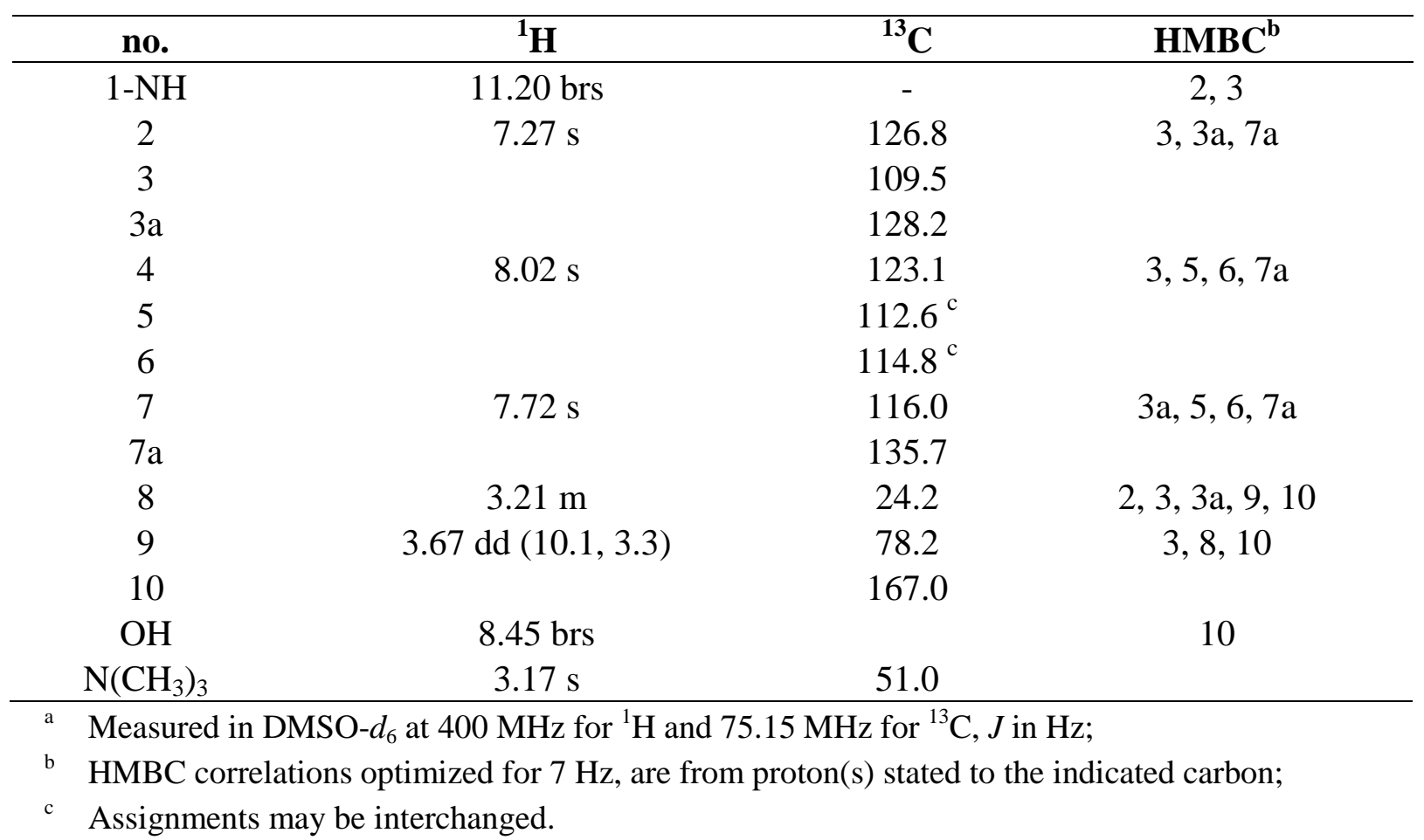

Several halogenated indoles bearing a $N, N, N$-trimethyltryptophane betaine moiety including di- and tri-iodo as well as both chlorine and iodine atoms on the indole nucleus have been reported from the Caribbean sponge Plakortis simplex [10,13]. The monobromoderivatives D-6- and L-6bromohypaphorine were previously reported from the Okinawan marine sponge Aplysina sp. and from the sponge Pachymatisma johnstoni, respectively [11,12] and the dibromoderivative 5,7-dibromo-L-hypaphorine was previously obtained by synthesis [12]. This is the first report of 5,6-dibromo-L-hypaphorine (9) as a natural product.

\subsection{Biological Activities of Compounds 1-9}

Compounds 1-9 were evaluated for their inhibitory activity against bee venom $\mathrm{PLA}_{2}$ and their antioxidant activity was estimated with the ORAC assay. The results from the in vitro assays are presented in Table 2 . In addition, their cytotoxicity against the human pharyngeal carcinoma cell line was also determined.

Dibromoindoles 5-9 exhibited the strongest inhibitory activity against bee venom PLA 2 , with 9 being identified as the most efficient $\mathrm{PLA}_{2}$ inhibitor of the series albeit with a weak $\mathrm{IC}_{50}$ value of $0.2 \mathrm{mM}$. 
Table 2. Biological activities of compounds 1-9.

\begin{tabular}{lcl}
\hline Compound & PLA $_{\mathbf{2}}^{\mathbf{a}}$ & ORAC $_{\mathbf{F L}} \mathbf{b}^{\mathbf{2}}$ \\
\hline (1H-Indol-3-yl)oxoacetamide (1) & $1.17 \pm 0.05$ & $\mathrm{nt}$ \\
(1H-Indol-3-yl)oxoacetic acid methyl ester (2) & $1.11 \pm 0.33$ & $\mathrm{nt}$ \\
6-Bromoindole-3-carbaldehyde (3) & $1.27 \pm 0.06$ & $\mathrm{nt}$ \\
Aureol (4) & $0.46 \pm 0.02$ & $0.29 \pm 0.03$ \\
5,6-Dibromotryptamine (5) & $0.62 \pm 0.01$ & $\mathrm{nt}$ \\
N-Methyl-5,6-dibromotryptamine (6) & $0.33 \pm 0.03$ & $\mathrm{nt}$ \\
$N, N$-Dimethyl-5,6-dibromotryptamine (7) & $0.77 \pm 0.05$ & $0.06 \pm 0.01$ \\
5,6-Dibromoabrine (8) & $0.30 \pm 0.01$ & $0.07 \pm 0.01$ \\
5,6-Dibromo-L-hypaphorine (9) & $0.20 \pm 0.01$ & $0.22 \pm 0.04$ \\
\hline
\end{tabular}

${ }^{\mathrm{a}} \mathrm{IC}_{50}$ values $(\mathrm{mM} \pm \mathrm{SEM} ; \mathrm{n}=2)$ on bee venom $\mathrm{PLA}_{2}$. Manoalide (positive control) $\mathrm{IC}_{50} 0.5 \pm 0.05 \mu \mathrm{M} .{ }^{\mathrm{b}}$ ORAC values are expressed as relative Trolox equivalent. Fluorescein (FL). Relative ORAC value $=[($ AUC product - AUC blank $) /($ AUC Trolox - AUC blank $)] \times($ molarity Trolox/molarity product), $(\mathrm{n}=3)$. Molarity in $\mu \mathrm{M}$. AUC: Area Under the Curve. AUC blank = AUC obtained for the control FL + AAPH. Ascorbic acid (positive control) $\mathrm{ORAC}_{\mathrm{FL}}$ $0.95 \pm 0.02 ;$ nt: not tested.

Figure 3. Fluorescein fluorescence decay curve induced by AAPH in the presence of Trolox or compounds 4, 7-9.

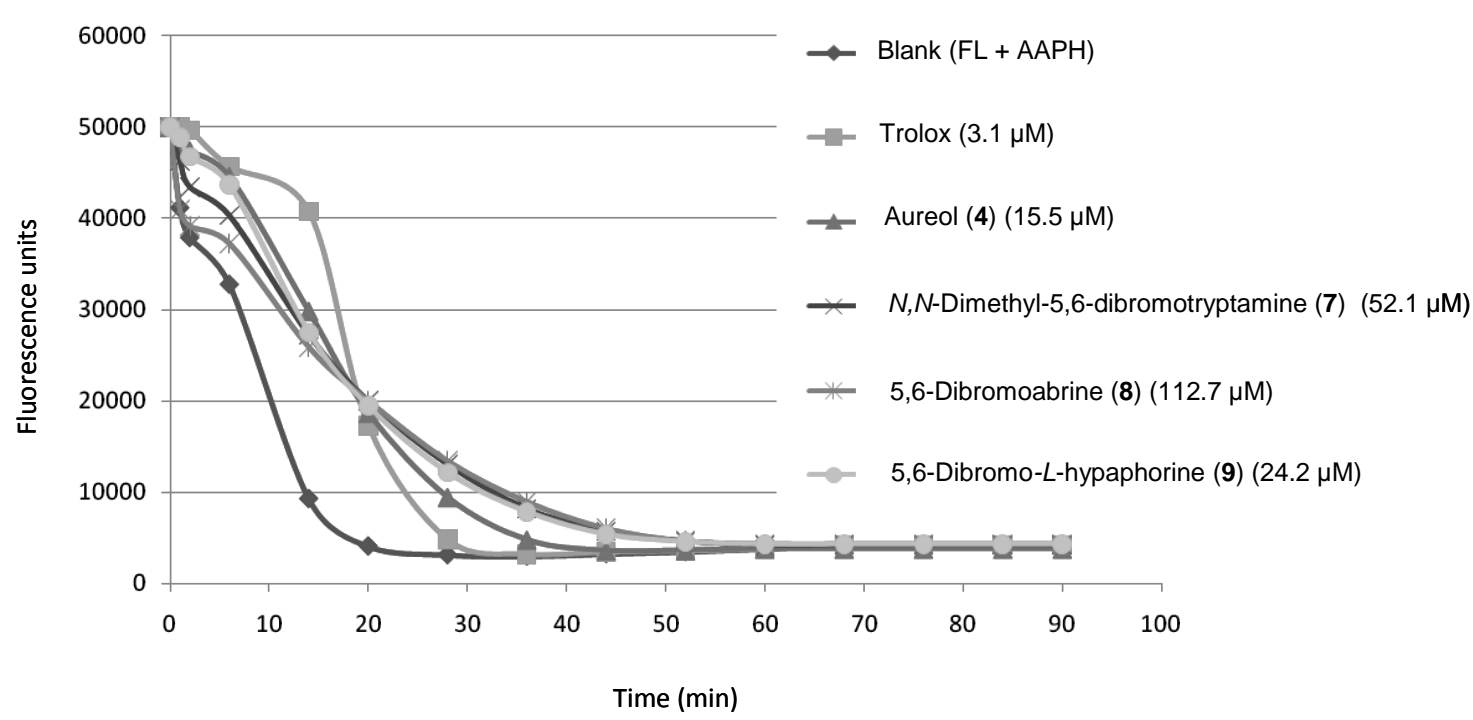

Compounds 4 and 7-9 displayed a positive antioxidant activity as first observed in the qualitative DPPH assay. Their antioxidant capacity was quantified in the ORAC assay measuring the loss of fluorescence of fluorescein (FL) in presence of the oxidative species AAPH (2,2'-azobis(2amidinopropane dihydrochloride)) and using $\operatorname{Trolox}^{\circledR}$ (6-hydroxy-2,5,7,8-tetramethylchroman-2carboxylic acid), a water-soluble analogue of vitamin E, as an anti-oxidant standard against which all the compounds were compared. Compounds 4 and $\mathbf{9}$ exhibited the strongest antioxidant effect with a relative ORAC value of 0.29 and 0.22 , respectively, as compared with Trolox which had value of 1 . Figure 3 shows the FL fluorescent decay curves of the four derivatives $(\mathbf{4}, \mathbf{7 - 9})$ tested at different concentrations in order to obtain a profile similar to Trolox. Compounds $\mathbf{7}$ and $\mathbf{8}$ were the least effective antioxidants. Compound $\mathbf{9}$ was 4 -fold less active than Trolox, displaying a similar curve at 
$24.2 \mu \mathrm{M}$, whilst compound 4 demonstrated a similar curve to Trolox at $15.5 \mu \mathrm{M}$, revealing it to be 3 -fold less active than Trolox.

None of the isolated compounds demonstrated any cytotoxicity towards KB cells at $10^{-4} \mathrm{M}$ except 4 $\left(\mathrm{IC}_{50} 5 \mu \mathrm{M}\right)$, already known for its antitumor activity [6,9].

\section{Experimental Section}

\subsection{General Experimental Procedures}

Optical rotations were recorded on a Perkin Elmer 341 polarimeter. UV spectra were recorded on a UVIKON 930 spectrometer and IR spectra were recorded on a FT-IR Shimadzu $8400 \mathrm{~S}$ spectrometer. NMR spectra were obtained on a Bruker AVANCE 400 spectrometer. HSQC and HMBC experiments were acquired at $400.13 \mathrm{MHz}$ using a ${ }^{1} \mathrm{H}_{-}{ }^{13} \mathrm{C}$ Dual probehead. HMBC spectra were optimized for $7 \mathrm{~Hz}$ coupling. Mass spectra were recorded on an API Q-STAR PULSAR I of Applied Biosystem. HPLC were performed with an Alliance apparatus (model 2695, Waters) equipped with a photodiode array detector (model 2998, Waters), an evaporative light-scattering detector (model Sedex 80, Sedere) and the software Empower. HPLC solvents were purchased from Carlo-Erba.

\subsection{Animal Material}

Specimens of Rhopaloeides odorabile (class Demospongiae, order Dictyoceratida, family Spongiidae) and Hyrtios sp. (class Demospongiae, order Dictyoceratida, family Thorectidae) were

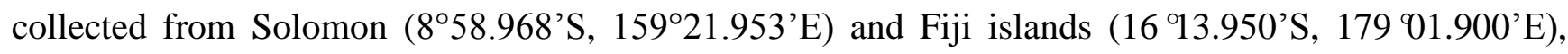
respectively. Samples were identified by John Hooper (Queensland Museum, Brisbane). A voucher specimen is available for each under the accession numbers G322727 (Rhopaloeides odorabile R3101) and G324650 (Hyrtios sp. R3268).

\subsection{Extraction and Isolation}

Lyophilized sponge sample Rhopaloeides odorabile $(20 \mathrm{~g})$ was extracted with $\mathrm{CH}_{2} \mathrm{Cl}_{2}(5 \times 200 \mathrm{~mL}$, sonicated each time for $15 \mathrm{~min}$ ) at room temperature. The five extracts were filtered, combined and concentrated under reduced pressure to yield $4 \mathrm{~g}$ of $\mathrm{CH}_{2} \mathrm{Cl}_{2}$ extract which was chromatographed on a silica gel (Merck) column using an initial gradient of cyclohexane/ethyl acetate from 80/20 to 60/40 followed by a second gradient of $\mathrm{CH}_{2} \mathrm{Cl}_{2}$ /acetone from 80/20 to 60/40. The $80 / 20 \mathrm{CH}_{2} \mathrm{Cl}_{2} /$ acetone fraction $(98 \mathrm{mg})$ exhibited anti-PLA 2 activity and was submitted to semi-preparative reversed-phase HPLC column chromatography (Interchim, Uptisphere C18 $7.8 \times 250 \mathrm{~mm}$ ) and eluted with increasing amounts of $\mathrm{MeOH}$ in $\mathrm{H}_{2} \mathrm{O}$ (flow rate: $3 \mathrm{~mL} / \mathrm{min}$, wavelength: $254 \mathrm{~nm}$ ) through a linear gradient (10\% to $100 \%$ of $\mathrm{MeOH}$ ) for $35 \mathrm{~min}$ and afforded three compounds 1-3 (1: $20 \mathrm{~min} \mathrm{MeOH} / \mathrm{H}_{2} \mathrm{O} 60 / 40$, 2: $24 \mathrm{~min} \mathrm{MeOH} / \mathrm{H}_{2} \mathrm{O}$ 70/30, and 3: $27 \mathrm{~min} \mathrm{MeOH} / \mathrm{H}_{2} \mathrm{O}$ 80/20 with amounts of 2.6, 1.0 and $1.1 \mathrm{mg}$, respectively).

Lyophilized sponge sample Hyrtios sp. (16 g) was extracted with $\mathrm{MeOH}(5 \times 200 \mathrm{~mL}$, sonicated each time for $15 \mathrm{~min}$ ) at room temperature. The five extracts were combined, filtered and concentrated under reduced pressure to yield $3 \mathrm{~g}$ of $\mathrm{MeOH}$ extract which was treated twice through a solvent partition using $\mathrm{CH}_{2} \mathrm{Cl}_{2}(150 \mathrm{~mL})$ and $\mathrm{MeOH} / \mathrm{H}_{2} \mathrm{O} 1: 1(150 \mathrm{~mL})$. After solvent evaporation, $0.9 \mathrm{~g}$ of an 
anti-PLA $\mathrm{P}_{2}$ active $\mathrm{CH}_{2} \mathrm{Cl}_{2}$ extract and $2.1 \mathrm{~g}$ of an anti-PLA $\mathrm{P}_{2}$ active $\mathrm{MeOH} / \mathrm{H}_{2} \mathrm{O}$ were obtained. The $\mathrm{MeOH} / \mathrm{H}_{2} \mathrm{O}$ extract was chromatographed on a C18 SPE column (Phenomenex) and eluted with $\mathrm{H}_{2} \mathrm{O}$, $\mathrm{H}_{2} \mathrm{O} / \mathrm{MeOH}$ 2:1, $\mathrm{H}_{2} \mathrm{O} / \mathrm{MeOH} 1: 2$ and $\mathrm{MeOH}\left(100 \mathrm{~mL}\right.$ of each). The anti-PLA $\mathrm{P}_{2}$ active fraction $\mathrm{H}_{2} \mathrm{O} / \mathrm{MeOH}$ 1:2 (220 mg) was eluted from an Sephadex LH 20 column (GE Healthcare) with MeOH to give an anti-PLA $\mathrm{P}_{2}$ active yellow fraction $(30 \mathrm{mg})$ which was further submitted to semi-preparative reversed-phase HPLC column chromatography (Interchim, Uptisphere C18 $7.8 \times 250 \mathrm{~mm}$ ) with increasing amounts of $\mathrm{CH}_{3} \mathrm{CN} / 0.1 \%$ formic acid in $\mathrm{H}_{2} \mathrm{O} / 0.1 \%$ formic acid as eluent (flow rate: $3 \mathrm{~mL} / \mathrm{min}$, wavelength: $254 \mathrm{~nm}$ ) through a linear gradient for $30 \mathrm{~min}$. Five peaks between 12 and 22 min were obtained, and further purified through an analytical reversed-phase HPLC column (Interchim, Uptisphere C18 $4.6 \times 250 \mathrm{~mm}$ ) with increasing amounts of $\mathrm{CH}_{3} \mathrm{CN} / 0.1 \%$ formic acid in $\mathrm{H}_{2} \mathrm{O} / 0.1 \%$ formic acid as eluent (flow rate: $1 \mathrm{~mL} / \mathrm{min}$, wavelength: $254 \mathrm{~nm}$ ) through a linear gradient for $30 \mathrm{~min}$ and yielded pure compounds $\mathbf{5 - 9}(0.5 \mathrm{mg}$ for $\mathbf{5}, 1.4 \mathrm{mg}$ for $\mathbf{6}, 1.3 \mathrm{mg}$ for 7, $1.7 \mathrm{mg}$ for $\mathbf{8}$, $3.0 \mathrm{mg}$ for 9). An aliquot of the crude $\mathrm{CH}_{2} \mathrm{Cl}_{2}$ extract $(0.4 \mathrm{~g})$ was chromatographed on a silica gel column, using a linear gradient of acetone in $\mathrm{CH}_{2} \mathrm{Cl}_{2}$ as eluent. The $50 \%$ acetone fraction afforded pure 4 (4 mg).

(1H-Indol-3-yl)oxoacetamide (1). White powder; ESI-MS m/z 189.0677 [M + H] ${ }^{+}$(calcd. 189.0658 for $\mathrm{C}_{10} \mathrm{H}_{9} \mathrm{~N}_{2} \mathrm{O}_{2}$ ); spectroscopic data matched those previously published [4].

(1H-Indol-3-yl)oxoacetic acid methyl ester (2). Yellow powder; ESI-MS m/z 204.0657 [M + H] $]^{+}$ (calcd. 204.0660 for $\mathrm{C}_{11} \mathrm{H}_{10} \mathrm{NO}_{3}$ ); spectroscopic data matched those previously published [4].

6-Bromoindole-3-carbaldehyde (3). Yellow needles; ESI-MS m/z 223/225, m/z $223.9713[\mathrm{M}+\mathrm{H}]^{+}$ (calcd. 223.9711 for $\mathrm{C}_{9} \mathrm{H}_{7} \mathrm{NO}^{79} \mathrm{Br}$ ); spectroscopic data matched those previously published [5].

Aureol (4). Brown powder; ESI-MS m/z $315.2312[\mathrm{M}+\mathrm{H}]^{+}$(calcd. 315.2324 for $\mathrm{C}_{21} \mathrm{H}_{31} \mathrm{O}_{2}$ ); spectroscopic data matched those previously published [6].

5,6-Dibromotryptamine (5). Light brown powder; ESI-MS m/z 317/319/321, m/z $316.9302[\mathrm{M}+\mathrm{H}]^{+}$ ( $m$ calcd. 316.9289 for $\mathrm{C}_{10} \mathrm{H}_{11} \mathrm{~N}_{2}{ }^{79} \mathrm{Br}_{2}$ ); spectroscopic data matched those previously published [7].

N-Methyl-5,6-dibromotryptamine (6). Light brown powder; ESI-MS m/z 331/333/335, m/z 330.9459 $[\mathrm{M}+\mathrm{H}]^{+}$(calcd. 330.9439 for $\mathrm{C}_{11} \mathrm{H}_{13} \mathrm{~N}_{2}{ }^{79} \mathrm{Br}_{2}$ ); spectroscopic data matched those previously published [7].

N,N-Dimethyl-5,6-dibromotryptamine (7). Light brown powder; ESI-MS $\mathrm{m} / z \quad 345 / 347 / 349$, $m / z 344.9557[\mathrm{M}+\mathrm{H}]^{+}$(calcd. 344.9602 for $\mathrm{C}_{12} \mathrm{H}_{15} \mathrm{~N}_{2}{ }^{79} \mathrm{Br}_{2}$ ); spectroscopic data matched those previously published [8].

5,6-L-Dibromoabrine (8). Light brown powder; $[\alpha]^{20}{ }_{\mathrm{D}}+17(c$ 0.05, MeOH-1 N HCl, 8:2) (lit.[9] +44 (c $0.05,1 \mathrm{~N} \mathrm{HCl}$ )); ESI-MS $\mathrm{m} / z$ 375/377/379, $\mathrm{m} / z 374.9361[\mathrm{M}+\mathrm{H}]^{+}$(calcd. 374.9338 for $\mathrm{C}_{12} \mathrm{H}_{13} \mathrm{~N}_{2} \mathrm{O}_{2}{ }^{79} \mathrm{Br}_{2}$ ); spectroscopic data matched those previously published [9].

5,6-Dibromo-L-hypaphorine (9). Pale yellow oil; $[\alpha]^{20}{ }_{\mathrm{D}}+28$ (c 0.06, $\left.\mathrm{MeOH}-1 \mathrm{~N} \mathrm{HCl}, 8: 2\right)$; UV (EtOH) $\lambda_{\max }(\log \varepsilon) 210$ (11,700), 230 (20,645), 294 (2,903) nm; IR (dry film) $v_{\max }$ 3402, 2924, 1597, $1357 \mathrm{~cm}^{-1}$; For ${ }^{1} \mathrm{H}$ and ${ }^{13} \mathrm{C}$ NMR data, see Table 1; ESI-MS $\mathrm{m} / \mathrm{z}$ 403/405/407, $\mathrm{m} / \mathrm{z}, 402.9667[\mathrm{M}+\mathrm{H}]^{+}$ (calcd 402.9651 for $\mathrm{C}_{14} \mathrm{H}_{17} \mathrm{~N}_{2} \mathrm{O}_{2}{ }^{79} \mathrm{Br}_{2}$ ). 


\section{4. $P L A_{2}$ Inhibition Assay}

Bioassay guided fractionation was based on a colorimetric bioassay [14]. Assays were performed in duplicate in 96 well plates and read on a CERES 900 spectrophotometer. Extracts $(250 \mu \mathrm{g})$ or fractions $(100 \mu \mathrm{g})$ dissolved in $10 \mu \mathrm{L}$ of DMSO were incubated with $2 \mu \mathrm{L}$ of a $\mathrm{PLA}_{2}$ solution $(1 \mathrm{mg} / \mathrm{mL}$ in DMSO) from Apis mellifera bee venom (Sigma) for $1 \mathrm{hr}$ at $25{ }^{\circ} \mathrm{C}$. Then $198 \mu \mathrm{L}$ of the substrate solution L- $\alpha$-lecithin (Sigma) $3.5 \mathrm{mM}$ containing Triton X-100 (7 mM), NaCl (100 mM), $\mathrm{CaCl}_{2}(10 \mathrm{mM})$ and red phenol $(0.055 \mathrm{mM})$ as colorimetric indicator, at $\mathrm{pH} 7.6$ were added and the absorbance at $550 \mathrm{~nm}$ read at time 0 and $5 \mathrm{~min}$. Percent inhibition of the enzyme activity was determined by comparison with a control without drug. Manoalide (Aldrich) was used as a positive control.

\subsection{Antioxidant Assays}

Qualitative DPPH screening: The potential antioxidant activity of crude extracts and pure compounds were screening using the scavenging activity of the DPPH (Sigma) free radicals. Active extracts were visualized by spraying a purple DPPH solution $(2 \mathrm{mg} / \mathrm{mL}$ in $\mathrm{MeOH})$ on a Tlc plate (Merck, Silica gel $60 \mathrm{~F}_{254}$ ), where compounds have been deposited. Immediate discoloration of DPPH around tested samples reveals their antioxidant activity.

Quantitative ORAC assay: The antioxidant activity of pure compounds was assessed with the ORAC assay. The ORAC assay is a kinetic assay measuring the decrease in fluorescence of fluorescein (FL) (Sigma) by adding the oxidative species AAPH (Aldrich, 2.2'-azobis(2amidinopropane dihydrochloride). Thus, antioxidant protection of compounds was evaluated over time. The antioxidant Trolox (Aldrich, 6-hydroxy-2,5,7,8-tetramethylchroman-2-carboxylic acid) was used as a positive control delaying the loss of FL fluorescence in a dose dependent manner $[15,16]$. The antioxidant activity is normalized to equivalent Trolox units to quantify the antioxidant activity of each compound. The assay was performed with a spectrofluorimeter Berthold Mithras LB 940. Reaction mixtures containing $25 \mu \mathrm{L}$ of different 2-fold dilutions of pure compounds (dissolved in phosphate buffer $75 \mathrm{mM}$, pH 7.4 containing 5\% DMSO) or Trolox $(200 \mu \mathrm{M}-12.5 \mu \mathrm{M})$ and $150 \mu \mathrm{L}$ of FL solution (10 $\mathrm{nM}$ in phosphate buffer) were distributed in 96 well microplates in triplicate and incubated at $37^{\circ} \mathrm{C}$ for $15 \mathrm{~min}$. Fluorescence was measured (Ex. $485 \mathrm{~nm}, \mathrm{Em} .520 \mathrm{~nm}$ ) every $90 \mathrm{sec}$ to determine the background signal. After 3 cycles of measurement, $25 \mu \mathrm{L}$ of an AAPH solution (240 $\mathrm{mM}$ in phosphate buffer) was added via an automated injector and 60 fluorescence measurements were taken over a $90 \mathrm{~min}$ time period. The final relative ORAC values for tested compounds were calculated by using a regression equation and were expressed as Trolox equivalents according to Ou et al. [16]. Trolox and ascorbic acid (Acros Organics) solutions were used as positive controls and FL solution with AAPH as blank.

\subsection{Cytotoxicity Assay}

The human KB cell line was obtained from ECACC (Salisbury, UK) and grown in D-MEM medium supplemented with $10 \%$ fetal calf serum (Invitrogen), in the presence of penicillin, streptomycin and fungizone in a $75 \mathrm{~cm}^{2}$ flask under $5 \% \mathrm{CO}_{2}$. Cells were plated in 96-well tissue 
culture microplates at a density of 650 cells/well in $200 \mu \mathrm{L}$ medium and treated $24 \mathrm{hrs}$ later with compounds dissolved in DMSO using a Biomek 3000 automate (Beckman-Coulter). Controls received the same volume of DMSO (1\% final volume). After $72 \mathrm{hrs}$ exposure MTS reagent (Celltiter 96 Aqueous One solution, Promega) was added and incubated for $3 \mathrm{hrs}$ at $37^{\circ} \mathrm{C}$ : the absorbance was monitored at $490 \mathrm{~nm}$ and results expressed as the inhibition of cell proliferation calculated as the ratio $\left[\left(1-\left(\mathrm{OD}_{490}\right.\right.\right.$ treated/OD $\mathrm{OD}_{490}$ control $\left.\left.)\right) \times 100\right]$. For $\mathrm{IC}_{50}$ determinations (50\% inhibition of cell proliferation) experiments were performed with compound concentrations ranging from $1 \mu \mathrm{M}$ to $100 \mu \mathrm{M}$ in duplicate.

\section{Conclusions}

In conclusion, our search for new inhibitors of $\mathrm{PLA}_{2}$ and/or antioxidant natural products has led to the investigation of specimens of the South Pacific marine sponges Rhopaloeides odorabile and Hyrtios sp. Eight indole derivatives including the new 5,6-dibromo-L-hypaphorine (9), and the sesquiterpene aureol (4) were isolated and their chemical structures were resolved by spectroscopic analysis. Evaluation of anti-PLA 2 and antioxidant activities of the series led to the identification of both 4 and 9 as potential antioxidant compounds. In contrast to 4, the new derivative 9 did not show any cytotoxic activity towards the human KB cancer cell line. Consequently, $\mathbf{9}$ could be promising in cosmetics and/or in pharmaceutics due to its anti-inflammatory and antioxidant potentials.

\section{Acknowledgements}

This work is part of the CRISP (Coral Reef Initiative in the South Pacific) project and granted by the Agence Française de Développement. We thank the Solomon and the Fiji Islands governments for allowing us to collect there, their Fisheries departments for their help and assistance. We thank the IRD diving team for the collection of the sponges, A. Blond and A. Deville (MNHN, Paris) for NMR spectra, A. Marie and L. Dubost (MNHN, Paris) for MS measurements. Brent R. Copp acknowledges the University of Auckland for research and study leave undertaken in Paris and the MNHN of Paris for welcoming him.

\section{References}

1. Blunt, J.W.; Copp, B.R.; Munro, M.H.; Northcote, P.T.; Prinsep, M.R. Marine natural products. Nat. Prod. Rep. 2011, 28, 196-268, and the previous reviews of this series.

2. Gul, W.; Hamann, M.T. Indole alkaloid marine natural products: An established source of cancer drug leads with considerable promise for the control of parasitic, neurological and other diseases. Life Sci. 2005, 78, 442-453.

3. Sugiyama, Y.; Ito, Y.; Suzuki, M.; Hirota, A. Indole derivatives from a marine sponge-derived yeast as DPPH radical scavengers. J. Nat. Prod. 2009, 72, 2069-2071.

4. Bao, B.; Zhang, P.; Lee, Y.; Hong, J.; Lee, C.-O.; Jung, J.H. Monoindole alkaloids from a marine sponge Spongosorites sp. Mar. Drugs 2007, 5, 31-39. 
5. Rasmussen, T.; Jensen, J.; Anthoni, U.; Christophersen, C.; Nielsen, P.H. Structure and synthesis of bromoindoles from the marine sponge Pseudosuberites hyalinus. J. Nat. Prod. 1993, 56, $1553-1558$.

6. Shen, Y.C.; Liaw, C.; Ho, J.R.; Khalil, A.T.; Kuo, Y.H. Isolation of aureol from Smenospongia sp. and cytotoxic activity of some aureol derivatives. Nat. Prod. Res. 2006, 20, 578-585.

7. Van Lear, G.E.; Morton, G.O.; Fulmor, W. New antibacterial bromoindole metabolites from the marine sponge Polyfibrospongia maynardii. Tetrahedron Lett. 1973, 4, 299-300.

8. Djura, P.; Stierle, D.B.; Sullivan, B.; Faulkner, D.J. Some metabolites of the marine sponges Smenospongia aurea and Smenospongia (Polyfibrospongia) echina. J. Org. Chem. 1980, 45, 1435-1441.

9. Tasdemir, D.; Bugni, T.S.; Mangalindan, G.C.; Concepcion, G.P.; Harper, M.K.; Ireland, C.M. Cytotoxic bromoindole derivatives and terpenes from the Philippine marine sponge Smenospongia sp. Z. Naturforsch. 2002, 57c, 914-922.

10. Campagnuolo, C.; Fattorusso, E.; Taglialatela-Scafati, O. Plakohypaphorines A-C, iodinecontaining alkaloids from the Caribbean sponge Plakortis simplex. Eur. J. Org. Chem. 2003, 284-287.

11. Kondo, K.; Nishi, J.; Ishibashi, M.; Kobayashi, J. Two new tryptophan-derived alkaloids from the Okinawan marine sponge Aplysina sp. J. Nat. Prod. 1994, 57, 1008-1011.

12. Raverty, W.D.; Thomson, R.H.; King, T.J. Metabolites from the sponge Pachymatisma johnstoni; L-6-bromohypaphorine, a new amino-acid (and its crystal structure). J. Chem. Soc., Perkin Trans. 1 1977, 1204-1211.

13. Borrelli, F.; Campagnuolo, C.; Capassa, R.; Fattorusso, E.; Taglialatela-Scafati, O. Iodinated indole alkaloids from Plakortis simplex. New plakohypaphorines and an evaluation of their antihistamine activity. Eur. J. Org. Chem. 2004, 3227-3232.

14. Motti, C.A.; Bourguet-Kondracki, M.-L.; Longeon, A.; Doyle, J.R.; Llewellyn, L.E.; Tapiolas, D.M.; Yin, P. Comparison of the biological properties of several marine sponge-derived sesquiterpenoid quinone. Molecules 2007, 12, 1376-1388.

15. Cao, G.; Prior, R.L. Measurement of Oxygen Radical Absorbance Capacity in Biological Samples. Methods Enzymol. 1999, 299, 50-61.

16. Ou, B.; Hampsch-Woodill, M.; Prior, R.L. Development and validation of an improved Oxygen Radical Absorbance Capacity assay using fluorescein as the fluorescent probe. J. Agric. Food Chem. 2001, 49, 4619-4626.

Samples Availability: Available from the authors.

(C) 2011 by the authors; licensee MDPI, Basel, Switzerland. This article is an open-access article distributed under the terms and conditions of the Creative Commons Attribution license (http://creativecommons.org/licenses/by/3.0/). 